\title{
GLOBAL WARMING AND CLIMATE CHANGE: SCIENCE AND POLITICS
}

\author{
Cliff Ollier \\ School of Earth and Environmental Studies, The University of Western Australia, Perth, Australia \\ Department of Geoecology and Palaeogeography, Maria Curie-Skłodowska University, Lublin, Poland
}

Manuscript received: September 5, 2012

Revised version: February 2, 2013

OluIER C., 2013. Global warming and climate change: science and politics. Quaestiones Geographicae 32(1), Bogucki Wydawnictwo Naukowe, Poznań, pp. 61-66. DOI 10.2478/quageo-2013-0008, ISSN 0137-477X.

AвSTRACт. The threat of dangerous climate change from anthropogenic global warming has decreased. Global temperature rose from 1975 to 1998, but since then has levelled off. Sea level is now rising at about 1.5mm per year based on tide gauges, and satellite data suggests it may even be falling. Coral islands once allegedly threatened by drowning have actually increased in area. Ice caps cannot possibly slide into the sea (the alarmist model) because they occupy kilometres-deep basins extending below sea level. Deep ice cores show a succession of annual layers of snow accumulation back to 760,000 years and in all that time never melted, despite times when the temperature was higher than it is today. Sea ice shows no change in 30 years in the Arctic. Emphasis on the greenhouse effect stresses radiation and usually leads to neglect of important factors like convection. Water is the main greenhouse gas. The $\mathrm{CO}_{2}$ in the ocean and the atmosphere are in equilibrium: if we could remove $\mathrm{CO}_{2}$ from the atmosphere the ocean would give out more to restore the balance. Increasing $\mathrm{CO}_{2}$ might make the ocean less alkaline but never acid. The sun is now seen as the major control of climate, but not through greenhouse gases. There is a very good correlation of sunspots and climate. Solar cycles provide a basis for prediction. Solar Cycle 24 has started and we can expect serious cooling. Many think that political decisions about climate are based on scientific predictions but what politicians get are projections based on computer models. The UN's main adviser, the IPCC, uses adjusted data for the input, their models and codes remain secret, and they do not accept responsibility for their projections.

KEY WORDS: global warming, temperature, sea level, ice caps, solar cycles

Clifford Ollier, School of Earth and Environmental Studies, The University of Western Australia, Perth, Australia, e-mail: cliff.ollier@uwa.edu.au

\section{Introduction}

Global warming and climate change have become dominant features in the way we run our lives, and in the often bizarre actions of governments. These dangerous beliefs are with us right now. People are still threatening us with the old line that Global Warming will bring Devastation! On May $3^{\text {rd }} 2012$ the US Defense
Secretary said ${ }^{1}$ : Climate change has a dramatic impact on national security. Rising sea levels, severe droughts, the melting of the polar caps, the more frequent and devastating natural disasters all raise demand for humanitarian assistance and disaster relief. Is there any truth at all in this?

1 http://www.defense.gov/news/newsarticle. aspx?id=116192, February 2, 2013 
The Global Warming Scare keeps changing form and name, so we have to be quite clear that it all started with Global Warming. The question is: Is anthropogenic carbon dioxide causing a dangerous rise in global temperature? The whole Climate Alarm is based on the assertions that:

1. The world is getting warmer;

2. The global warming is caused by human-produced $\mathrm{CO}_{2}\left(\mathrm{AGW}^{2}\right)$.

All the rest - rising sea level, melting ice sheets, drowning polar bears, and hundreds more - are additional alarms based on the assumption of global warming. Whole books have been written on the topic such as Carter (2010), and this article is a very brief synopsis.

\section{Temperature}

Warming has ceased! In a press release of April 2, 20123, it was announced that: New UK Met Office global temperature data show that there has been no global warming in the past 15 years - a timescale that challenges current models of global warming. The graph shows the global annual average temperature since 1997. No statistically significant trend can be discerned from the data. The only statistically acceptable conclusion to be drawn from the data is that between 1997 and 2011 temperature has remained constant, with a global temperature of $14.44+/-0.16$ deg C (2 standard deviations). On Christmas Eve, 2012, the UK Met Office said global temperatures were likely to be lower than it previously forecast because of 'natural variability of the climate system' (Ingham 2013).

Land based data are somewhat unreliable, but the hottest recent year was 1998. The warmest years of the twentieth century were in the 1930s. In fact the temperature varies regularly. The Earth's warming from 1915 to 1940 was just about as strong as the "scary" 1975 to 1998 warming in both scope and duration - and occurred too early to be blamed on human-emitted $\mathrm{CO}_{2}$. The cooling from 1940 to 1975 defied the Greenhouse Theory, occurring during the first big surge of man-made greenhouse emissions.

AGW - Anthropogenic Global Warming

http://www.thegwpf.org/no-global-warming-for15-years/, February 3, 2013
Satellite data show global temperature is essentially unchanged in 30 years.

Sea ice shows no change in 30 years, though every annual retreat is heralded by alarmists as proof of AGW.

Ocean temperatures are more important than land temperatures because the ocean holds much more heat than the atmosphere. Since 2004 the Argo observation system of 3000 buoys has been measuring the sea temperature. The machines go down as far as two kilometres and surface every ten days to send out their data, which shows a cooling trend.

Because we have data to great depths we know there is nowhere for the heat to be hiding. The greenhouse warming hypothesis requires a rise in temperature. The observed cooling trend show it is not happening, so the hypothesis should be rejected.

\section{The long term history of temperature}

On the long geological time scale there were major glaciations in the Quaternary, Permian, Eocambrian and at least five Precambrian glaciations. We are living in an interglacial in the Quaternary Glaciation, which itself has minor maxima and minima:

The main warming periods are:

- Egyptian (Old Kingdom),

- Minoan,

- Roman,

- Mediaeval 1000 to 1300 ,

- 20thcentury.

The main cold periods are:

- Dark ages,

- Little Ice Age 1300 to 1850, including:

- Maunder minimum 1645 to 1715

- Dalton Minimum 1790 to 1820

We shall see later that these correspond to solar maxima and minima.

Central England has the longest record of thermometer readings, back to 1661 . It shows the Little Ice Age, including the Dalton Minimum (the last time the River Thames froze over) and the even colder Maunder Minimum. The later years are affected by heat island effects. Data 
from the rural US go back to 1893, and avoids heat islands. The hottest year was 1936.

\section{Sea level}

Sea level has been generally rising since the end of the last ice age. Based on tide gauge data a generally accepted rise is of about $1.5 \mathrm{~mm}$ per year since end of last glacial. Direct studies of sea level are showing only small rises. You can see the sea level data for yourself for the United States and a few other countries ${ }^{4}$. Most stations show a rise of sea level of about $2 \mathrm{~mm}$ per year, but note the considerable variation even within a single state.

A recent review of sea level change is provided by Morner (2012), including analysis of satellite data. He writes that the raw data from the TOPEX/POSEIDON sea-level satellites, which operated from 1993-2000, show a slight uptrend in sea level, but if the distorting effects of the Great El Niño Southern Oscillation of 1997/1998 are excluded the sea-level trend is zero. The GRACE gravitational-anomaly satellites data show that sea level fell slightly from 2002-2007.

The European satellite, Evisat, provided possibly the best available data. It showed falling sea level since it was launched in 2002, and for the last two years decline is continuing at $5 \mathrm{~mm} /$ yr. Unfortunately Evisat broke down on April $8^{\text {th }}$ 2012. NASA also reported in 2011 that Global sea level this summer is a quarter inch lower $(\sim 6$ $\mathrm{mm}$ ) than last summer ${ }^{5}$.

Two favourites of sea level alarmists are the coral islands of Tuvalu and the Maldives. Sea level measurements for Tuvalu (and ten other stations) can be seen on Fig. 13 on the Australian Bureau of Meteorology website ${ }^{6}$. You can see for yourself that sea level is virtually stable. Yet since they are close to sea level it was repeatedly claimed that these islands are in imminent danger. Webb and Kench (2010) presented the first quantitative analysis of physical changes in 27 atoll islands in the SW Pacific (including Tuvalu) over a 19 to

\footnotetext{
4 http://tidesandcurrents.noaa.gov/sltrends/sltrends. shtml, February 2, 2013

5 http://sealevel.jpl.nasa.gov/, February 2, 2013

6 http://www.bom.gov.au/ntc/IDO60101/ IDO60101.200809.pdf, February 2, 2013
}

61 year period. They found that $86 \%$ of islands remained stable $(43 \%)$ or increased in area (43\%). Coral islands are increasing in size because coral grows: the reef is a living thing. Coupled with erosion and deposition the coast is modified, but there is no danger of drowning. The Maldives were studied by a team of geomorphologists led by the doyen of sea level studies, Niklas AxelMorner, and they found no evidence of sea level rise (Morner et al. 2004). Alarmists claim there will be a rise several metres by the end of the century. Robin Williams, an Australian alarmist who runs the so-called Science Show on national radio, has even claimed $100 \mathrm{~m}$.

\section{Glaciers and ice caps}

There are two kinds of ice mass in the world, alpine type glaciers, the 'rivers of ice', and ice caps or ice sheets, mainly those of Greenland and Antarctica. The climate alarmists have a false model for both! Basically they believe that the ice is sliding downhill, lubricated by meltwater. With global warming there is more meltwater and the ice slides ever faster. James Hansen even claimed that all the ice sheets could slide into the sea in a few decades! Alpine glaciers do not slide on a lubricated base. This was the idea of De Saussure in 1779, but experiments with sticks across a glacier by Agassiz and Forbes in 1845 showed the middle flows faster than the edges. They were clear that this shows we do not have a rigid mass of ice sliding on its base. In reality the lower part flows plastically carrying a rigid upper part that cracks up making crevasses.

Ice caps cannot possibly slide into the sea because they occupy kilometres-deep basins extending below sea level, and the ice would have to slide uphill (Ollier 2010). Furthermore the deep ice cores show a succession of annual layers of snow accumulation back to 760,000 years. In all that time there has been no melting at the surface, despite times when the temperature was higher than that of today. But the weight of the icecap eventually becomes sufficient to exceed the yield stress of ice, and the lower part of the ice starts to flow, assisted by geothermal heat. This is in no way related to the temperature at the surface, and of course not related in any 
way to $\mathrm{CO}_{2}$. In Greenland the icecap ice flows out through gaps in the mountain rim, and the outflow glaciers have many of the properties of alpine glaciers. Antarctica has similar behaviour, though more complex. Remember Antarctica is about $30 \%$ bigger than Europe, and there are some mountain ranges under the ice. Also note that the Greenland icecap is about 3 million years old and the Antarctic icecap is about 33 million years old. They are not simply responding in unison to global temperatures.

Glaciers and icecaps have a budget, with accumulation, flow and melting or breaking off (icebergs). It takes hundreds or thousands of years for ice to flow from source to end, so the position of the end today is not just the result of today's climate, but of precipitation long ago. Every break-up of an ice shelf to produce an ice berg is treated by the alarmists as a signal of global warming. But for glaciers that reach the sea this is the normal process at the terminus. The icecaps never did just flow for ever until they reached the equator! Tourists flock to see the Hubbard Glacier in Alaska where frequent breaking at the ice front produces icebergs the size of a 7-story building. It seems an impressive loss, but the Hubbard glacier has been advancing at $25 \mathrm{~m} \mathrm{a}^{-1}$ since it was first measured in 1895. In 1999 it was even reported to be advancing at $2 \mathrm{~m}$ per day. Today the icecaps are increasing in thickness, and many glaciers are advancing, though some are in retreat. The pattern is complex and certainly not a simple response to global warming or manmade carbon dioxide since 1945.

\section{The greenhouse effect and greenhouse gases}

The greenhouse effect is real, but trivial. Water is the major greenhouse gas, about four to ten times more effective than $\mathrm{CO}_{2}$. We cannot give an absolute number because the amount of water vapour in the air varies a great deal. $\mathrm{CO}_{2}$ is minor $(0.04 \%)$, and methane even less $(0.001 \%)$ and very variable with no detectable effect on climate.

So how does the IPCC get a runaway greenhouse effect? They apply an enormous amount of compounding water vapour feedback to a small amount of heating from $\mathrm{CO}_{2}$. At their worst, the IPCC models take one degree of heating and turn it into 6.4 degrees.

Emphasis on the greenhouse effect stresses only radiation and usually leads to neglect of other factors, especially convection which uses lots of energy.

\section{Carbon dioxide, $\mathrm{CO}_{2}$}

Carbon dioxide requires extra treatment, as it is the alleged cause of global warming, and the fundamental reason for a carbon tax and calls to cut the carbon footprint. The ultimate source of $\mathrm{CO}_{2}$ is volcanic eruption; the sink is limestone, where most of the world's $\mathrm{CO}_{2}$ is stored. The $\mathrm{CO}_{2}$ content of the atmosphere has been much greater in the geological past, without catastrophe. The amount of $\mathrm{CO}_{2}$ in the atmosphere is a mere $0.04 \%$, and it is indeed increasing, but the increase started long before 1945 when AGW is supposed to start.

The ocean is a huge sink and holds much more $\mathrm{CO}_{2}$ than the atmosphere. There is an equilibrium between the $\mathrm{CO}_{2}$ in the ocean and the atmosphere, and if we were somehow able to remove it from the atmosphere the ocean would give out more $\mathrm{CO}_{2}$ to restore the equilibrium. Although many countries are attempting it, at great expense, the sequestering of $\mathrm{CO}_{2}$ is pointless. Cold seas hold more $\mathrm{CO}_{2}$ than warm seas. Climate alarmists want to cool the world (by preventing global warming), so their policy would add more $\mathrm{CO}_{2}$ to the ocean, which would increase their second problem of alleged ocean acidification.

Rising $\mathrm{CO}_{2}$ levels follow temperature rise as recorded in ice cores. The sequence of events during Termination III suggests that the $\mathrm{CO}_{2}$ increase lagged Antarctic deglacial warming by $800 \pm 200$ years and preceded the Northern Hemisphere deglaciation (Caillon et al. 2003). If $\mathrm{CO}_{2}$ caused rising temperature it should be the other way round.

\section{Ocean acidification}

To demonise $\mathrm{CO}_{2}$ again, a false claim is made that human production of $\mathrm{CO}_{2}$ will cause the oceans to become acid (e.g. Kolbert 2011). The ocean is alkaline, with a $\mathrm{pH}$ of about 8.2, and has never been acid in all Earth history, indicated by 
the preservation of marine limestones. Increasing $\mathrm{CO}_{2}$ might make the ocean less alkaline but never acid (Idso et al. 2010).

Photosynthesis is the basis of life. It is the process whereby plants use $\mathrm{H}_{2} \mathrm{O}$ and $\mathrm{CO}_{2}$ and sunlight to synthesise sugar and other organic molecules. And animals are dependent on plants to provide their energy. If $\mathrm{CO}_{2}$ gets too low, plant growth shuts down, and the more we take carbon dioxide above that minimum critical level, the safer life on this planet will be. On land and in the sea, living organisms thrive on increased $\mathrm{CO}_{2}$. The present $\mathrm{CO}_{2}$ level is $394 \mathrm{ppm}$ and the pre-industrial level $280 \mathrm{ppm}$. a $\mathrm{CO}_{2}$ level of 1,000 ppm is the level at which commercial operators like to run their greenhouses and commonly get an increase in crop yield of about $30 \%$. Both experimental and observational evidence shows increased $\mathrm{CO}_{2}$ enhances marine life. a favourite diving site in Papua New Guinea called the Bubble Bath has volcanogenic $\mathrm{CO}_{2}$ streaming through the water, and life flourishes (Starck 2010).

The climate alarmists usually try to take the high moral ground when they claim that reducing $\mathrm{CO}_{2}$ will Save the Planet, but the more carbon dioxide you put into the atmosphere, the more you are Helping All Living Things on the planet and of course that makes you a better person. Yet governments now tell us $\mathrm{CO}_{2}$ is a pollutant! When global warming failed to occur and people were getting bored, the US Environment Protection Agency declared $\mathrm{CO}_{2}$ was a pollutant. There is absolutely no evidence for this. For much life on the planet we are in a $\mathrm{CO}_{2}$-poor environment.

Green propaganda films show chimneys emitting black clouds, and cooling towers belching white clouds. These are soot and water (distilled, pure water!), but the subliminal message is that this is pollution. Remember $\mathrm{CO}_{2}$ is invisible. The propaganda is pure lies, and stooping to such a level suggests the alarmists cannot make a case with true science.

\section{The Sun}

The sun is the major control of climate, but not simply by irradiation, and not by irradiation modified by greenhouse gases. Nobody can deny that climate varies, so what causes variation in energy gained from the sun?

Milankovitch cycles result from changes in the distance to the sun, but more important are sun spots and solar cycles. There is a very good correlation of sunspots and climate. Periods of low sunspots go with colder climate. The probable mechanism was discovered by Svensmark et al. (2007). During periods of low solar activity (solar minima), more cosmic rays reach Earth, potentially creating ultra-small aerosol particles which are precursors to cloud condensation nuclei. This causes more low level cloud formation, more low level clouds means more sunlight reflected back into space, which in turn means less heating of the Earth's surface and atmosphere. Archibald (2007) pointed out that the longer a solar cycle lasts, the cooler the following solar cycle will be. Solar cycles are normally 11 years long, but solar cycle 23 lasted 12.5years. Solar Cycle 24 has started and we can expect serious cooling. Solar Cycle 23 seems to resemble most closely Solar Cycle 4, and if the trend continues we should be heading for a Dalton Minimum. Ken Schatten, the solar physicist with the best track record in predicting solar cycles, suggests we could be heading for a Maunder Minimum. There is also a De Vries cycle of 210 years, and the last one was 201 years ago, so the next one is due. If the two cycles are superimposed it will be even colder.

\section{Models, predictions and projections}

Many think that the political decisions concerning climate are based on scientific predictions. This is quite untrue: what the politicians get are projections based on models. What is the difference, and why is it never made clear? Models depend on assumptions, what you put in (data), the program, and conclusions drawn from the output.

The United Nation's main adviser, the Intergovernmental Panel on Climate Change uses adjusted data for the input (mostly from the discredited Climate Research Unit), and their computer models and codes remain secret - not a scientific procedure. Remember how the IPCC gets a runaway greenhouse effect? They apply an enormous amount of compounding water vapour feedback 
and IPCC models take one degree of heating and turn it into 6.4 degrees. They do not give predictions of the future, but only computer projections. Furthermore they do not take responsibility for the alarm they generate.

The Australian CSIRO, for example, has legal disclaimers for their scary predictions: This report relates to climate change scenarios based on computer modelling. Models involve simplifications of the real processes that are not fully understood. Accordingly, no responsibility is accepted by the CSIRO for the accuracy of forecasts or predictions inferred from this report or for any person's interpretations, deductions, conclusions or actions in reliance on this report ${ }^{7}$. Any allegedly scientific document that needs a legal disclaimer is clearly not science. And if CSIRO is not giving advice for which it takes responsibility they may as well be disbanded. Australian government ministers (and their advisers) claim that their decisions are based on a scientific consensus but especially the advice of IPCC and CSIRO. But both of these organisations deny making predictions, and refuse to be responsible for their computer's projections. Computers are still not clever enough to take responsibility, so presumably it is the government, through lack of due diligence, that is responsible for the expensive and ineffective actions it is now implementing to combat the alleged human-induced dangerous Global Warming. The argument can be extended to all the other governments in the world that are impoverishing their nations by imposing extravagant policies based on global warming.

\section{References}

ARChiBALD D., 2007. Climate Outlook to 2030. Energy and Environment, 18: 615-619.

Caillon N., Severinghaus J.P., Jouzel J., Barnola J.-M., JiANCHENG K. \& LiPENKov V.Y., 2003. Timing of Atmospheric $\mathrm{CO}_{2}$ and Antarctic Temperature Changes across
Termination III. Science, 299: 1728-1733. DOI: 10.1126/ science.1078758.

CARTER R.M. 2010. Climate: the counter-consensus. Stacey International, London. pp. 315.

IDso S., IDso K. \& IDso C., 2010. The Real Ocean Acidification Story. $\mathrm{CO}_{2}$ Science, 13, 9, 3 March 2010. Online: http:// www.co2science.org/articles/V13/N9/EDIT.php, February 2, 2013.

INGHAM J., 2013. Surprise surprise...Global Warming has stopped, admits Met Office. Daily Express, January $9^{\text {th }}$. Online: http://www.express.co.uk/posts/view/369564/ Surprise-Surprise-Global-warming-has-stalled-admitsMet-Office, February 2, 2013.

Kolbert E. 2011. The Acid Sea. National Geographic, April. 100-121.

Mörner N.-A., 2012. Sea Level Is Not Rising. SPPI Reprint Series, December 6, 2012. Online: http:/ / scienceandpublicpolicy.org/blog_watch/sea_level_is_not_rising.html, February 2, 2013.

Mörner N.-A., Tooley M.J. \& Possnert G., 2004. New perspectives for the future of the Maldives. Global \& Planetary Change, 40: 177-182. DOI: 10.1016/S0921-8181(03)001085.

OlLier C.D., 2010. Glaciers - science and nonsense. Geoscientist, 20(3): 16-21.

StARCK W., 2010. Observations on growth of reef corals and sea grass around shallow water geothermal vents in Papua New Guinea. This paper was originally published in Quadrant Online on 15 March, 2010 but is no longer on their website. Now online: http:/ / www.goldendolphin. com/WSarticles/CO2\% 20Vents \% 20in \% 20PNG.pdf, February 2, 2013.

Svensmark H., Pedersen O.J., Marsh P., Enghoff M. \& UggerHOJ U., 2007. Experimental evidence for the role of ions in particle nucleation under atmospheric conditions. Proceedings of the Royal Society of London, a 463: 385-96. DOI: 10.1098/rspa.2006.1773.

Webb A.P. \& Kench P.S., 2010. The dynamic response of reef islands to sea level rise: evidence from multi-decadal analysis of island change in the central pacific. Global and Planetary Change, 72: 234-246. DOI: 10.1016/j.gloplacha.2010.05.003.

\section{Further reading}

BOOKER C., 2011. The Real Global Warming Disaster. Continuum. pp. 368. (This book very clearly recounts the history of the Global Warming/Climate Change debate in great detail.)

La Framboise D., 2011. The Delinquent Teenager who was mistaken for a World Top Climate Expert. Ivy Avenue Press. pp. 235. (An account of the history and methods of the IPCC.) 